\title{
Applying Linear Programming in Business Decision Making: A Case of Profit Maximization of a Commercial Housing Development
}

\author{
Uswatun Hasanah $^{1} \quad$ Susilahudin Putrawangsa ${ }^{2} \quad$ Danang Tejo Kumoro ${ }^{1}$ \\ 1.Informatics Engineering Department, Bumigora University, Mataram, Indonesia \\ 2.Mathematics Education Department, State Islamic University of Mataram, Indonesia
}

\begin{abstract}
The current research shows how to utilize the linear programming to perform a profit maximization on two economic cases and analyze the sensitivities of the obtained solutions to identify the key factors influencing the solution, which then can be used as the basis to decide the most profitable business. The case of the current study is identifying the most profitable project of two housing developments in Indonesia. The linear programming of the simplex method is applied to address the problem. The findings indicate that the linear programming solution and its sensitivity analysis effectively and efficiently inform and assist businessmen in identifying the most profitable project under the given constraints. In this case, the linear programming with its sensitivity analysis asserts that selecting a business activity based merely on the amount of its apparent profit may lead to an improper business decision. An example from the current study shows that although the second project yields a higher profit, the solution of the linear programming suggests that the first project is more relevance to its market demand and it needs less capital than that the second project. The higher profit obtained of the second project tends to be relative or fictitious since both projects result in the same return on investment (ROI). Moreover, the sensitivity analysis indicates that the optimization solution of the first project is more stable to change than that of the second project. Keywords: Profit Optimization, Return on Investment, Market Demand, Sensitivity Analysis, Simplex Method DOI: $10.7176 /$ EJBM/11-19-06
\end{abstract}

Publication date:July 31 st 2019

\section{Introduction}

Various approaches of profit maximization have been widely applied to help decision-makers in taking essential business steps to optimize their business profit (e.g. Stripling, 2018; Hasanah \& Ahmad, 2018; Levitt, 2015; Liu, 2006; Khanra, Maiti, \& Maiti, 2015; Ahmadi-Javid, Amiri, \& Meskar, 2018; Mazidi, et al., 2018). Among them is Linear Programming. It has been proven to be one of the most blossomed quantitative approaches to decision making (Anderson et al., 2012). Its applications have been reported in a wide range of industry and business activities, such as production decisions (e.g. Levitt, 2015; Yahya, Garba, \& Ige, 2018; Rohmah, et al. 2018; Maurya, et al., 2015), capital budgeting and financial planning (e.g. Wu \& Ge, 2012; Wijeratne, \& Harris, 1984), distribution system (Goetschalckx, Vidal, \& Dogan, 2012), project selection (e.g. Aboelmagd, 2018), transportation (Guo \& Xu, 2016), staffing (e.g. Florez, et al. 2012; Cezik \& L'Ecuyer, 2006), scheduling (Torres et al. 2014; García-Nieves, 2019), farming (Jaslam, et al., 2017; Hassani \& Akhtar, 2015; Igwe, Onyenweaku \& Tanko, 2013), etc.

Moreover, an essential relationship between linear programming, profitability and resource allocations is well identified. Onoriode \& Ighoroje (2018), for example, found that the linear programming method is a highly effective strategy and tool for organizing resource allocations that lead to profit maximization.

Despite the numerous application of linear programming in industries and business, a few research has been reported about the utilization of the linear programming for business decision making in selecting the most profitable business activity.

Since market demand is known as one of the most influencing economic factors on business profitability (Narver \& Slater, 1990; Guide, Teunter, \& Wassenhove, 2003; (Hildenbrand, 1994), the context of profit maximization with respect to market demand of a commercial housing development is taken as the case of the current research.

Hence, the current research clarifies the modelling process of the profit maximization subject to market demand by means of linear programming taking the case of housing development. The result of the optimization and its sensitivity are used to identify the key factors influencing the profit maximization and use as the basis to decide the most profitable project.

\section{Methodology}

The current study demonstrates the use of linear programming for profit maximization with regards to market demand and other related constraints. It is a case study taking the context of commercial housing development in Indonesia. The data are taken from an Indonesian housing firm (a housing developer) where they intend to develop 
a commercial housing location consisting of three types of houses. The challenge faced by the developer is selecting one of two potential locations for housing development. It is known that both locations have identic constraints, except on their market demand. There is a slight difference in the market demand in the two locations. The developer asks for the most profitable location if it has to choose one of the two locations.

Profit maximization approach is used to address the challenge. The output of the profit maximization model of the current study is expressed in the form of a linear programming statement proclaiming the objective and the constraint functions of the optimization, including its optimization solution. The analysis of the obtained optimization solutions and their sensitivities are performed to identify the key factors influencing the profit maximization and use as the basis to decide the most profitable project.

In formulating the model for profit maximization, the current study employs the linear programming method (i.e. the simplex method) using QM software. There are five stages of linear programming procedures applied, namely (1) determining decision variables, (2) formulating the objective function, (3) determining and modelling the constraint functions, (4) formulating the model of the linear programming statement subject to the given constraints, (5) calculating and analyzing the optimization solution of the linear programming statement, and (6) conducting sensitivity analysis to identify the key factors influencing the optimization solution.

\section{Results and Discussion}

Profit maximization relating to unit production is a crucial issue and a complex problem for most industrial companies or firms, especially once they face a considerable number of limitations. Although the amount of profit obtained from the selling a product, suppose product $\mathrm{A}$, is significantly higher than those of product B, it is not always a right decision to produce more $\mathrm{A}$ than $\mathrm{B}$ in order to obtain an optimal profit. The producers should consider a bunch of factors that influence their business activities, such as the available resource (capitals, materials, and workforce), market demand, return on investment, policy restriction, etc.

As mentioned before, the case discussed in the current study is the developers' challenge in deciding two potential projects of housing development that have similar constraints with a minor difference in market demand. Since the developer has to choose one of the two projects, the question is which location is more profitable.

Profit maximization of linear programming (i.e. the simplex method) using QM Software is used to address the challenge consisting of six steps, namely (1) determining decision variables, (2) formulating the objective function, (3) determining and modelling the constraint functions, (4) formulating the model of the linear programming statement subject to the given constraints, (5) calculating and analyzing the optimization solution of the linear programming statement, and (6) conducting sensitivity analysis to identify the key factors influencing the optimization solution. Each of the steps is discussed in this section. Some important remarks regarding the findings are elaborated in the end of the current sections.

\subsection{The Case Description}

Due to capital and resource limitation, a housing developer (an Indonesian firm) has to choose one of two available places to develop a residential location. They will build a similar variance of houses (types and size) in both locations, and they also face similar constraints relating to capital and land resources and workforce. The firm plan to build three types of houses, so-called T40, T70, and T100. The capital production for each type of houses is $75 \%$ of the price. T40 is offered to the market at a price of 400 million. Whereas T70 and T100 are 600 million and 720 million respectively. Currently, the developer has only 50,000 million in total for capital production.

Each type of houses is built on a fixed size of the area where T40 is on 100 square meters, and T70 is on 200 square meters. Meanwhile, T100 occupies 350 square meters. In total, there is 20 hectares area available for the house construction in each location, excluding the space area for public facilities.

There are 450 workers available at the moment to work either at the first location or at the second location. For the efficiency purpose, the firm restricts the number of workers in each type of houses, where it should be 3 workers for constructing T40, 4 workers for T70 and 5 workers for T100.

Considering the local government policy about residential development, the developer decides to build maximally 200 units in each location regardless of the house types in order to avoid constructing own electrical power control that may cause a capital increase.

However, the market demands for the houses at the two locations are slightly different. According to their data of registered buyers (the list of consumers who have registered to buy the houses), they identified that there are around $60 \%$ of their costumers intending to buy T40 and about $30 \%$ and $10 \%$ for T70 and T100 respectively for the first location. Meanwhile, the market demand for the second location is $55 \%, 30 \%$ and $15 \%$ for T40, T70 and T100 respectively.

The firm's owners question about which location is more profitable under the given constraints and differences. 
Table 1. The variables and the constraints of the case of the housing development of the current study

\begin{tabular}{|c|c|c|c|c|c|}
\hline \multirow{2}{*}{$\begin{array}{l}\text { Variables and } \\
\text { Constraints }\end{array}$} & \multicolumn{3}{|c|}{ Type of Products } & \multirow{2}{*}{$\begin{array}{c}\text { Available } \\
\text { Resource and } \\
\text { Restriction }\end{array}$} & \multirow[b]{2}{*}{ Note } \\
\hline & $\mathrm{T} 40$ & $\mathrm{~T} 70$ & T100 & & \\
\hline $\begin{array}{l}\text { Land Size (square } \\
\text { meter) }\end{array}$ & 100 & 200 & 350 & 20,000 & $\begin{array}{l}\text { excluding area for residential street } \\
\text { and other public facilities }\end{array}$ \\
\hline Price (million) & 400 & 600 & 720 & - & Fixed price \\
\hline $\begin{array}{l}\text { Capital Production } \\
\text { (million) }\end{array}$ & 300 & 450 & 540 & 50,000 & $75 \%$ of the price \\
\hline Profit (million) & 100 & 150 & 180 & - & $25 \%$ of the price \\
\hline Workforce (person) & 3 & 4 & 5 & 450 & Available at the moment \\
\hline $\begin{array}{l}\text { Unit } \\
\text { (house) }\end{array}$ & - & - & - & 200 & $\begin{array}{l}\text { To avoid a capital increase on the } \\
\text { project. }\end{array}$ \\
\hline $\begin{array}{l}\text { Market Demand on } \\
\text { the first site }\end{array}$ & $60 \%$ & $30 \%$ & $10 \%$ & - & $\begin{array}{l}\text { The proportion is based on the } \\
\text { registered buyers }\end{array}$ \\
\hline $\begin{array}{l}\text { Market Demand on } \\
\text { the second site }\end{array}$ & $55 \%$ & $30 \%$ & $15 \%$ & & $\begin{array}{l}\text { The proportion is based on the } \\
\text { registered buyers }\end{array}$ \\
\hline
\end{tabular}

To address the challenge, profit maximization of linear programming is applied consisting of six steps, namely (1) determining decision variables, (2) formulating the objective function, (3) determining and modelling the constraint functions), (4) formulating the model of the linear programming statement subject to the given constraints, (5) finding the optimization solution based on the model of the linear programming statement, and (6) conducting sensitivity analysis to identify the key factors influencing the optimization solution. Each of the steps is discussed in this section. Each step is described in the following paragraphs.

\subsection{The Decision Variables}

In the context of profit maximization, the decision variables are the quantities that the decision makers would like to specify and control in order to optimize their profit. In other words, the decision variables are the values that are intended to be optimized to gain a maximal profit.

In the case of the current study, the number of unit production for each type significantly determines the obtained profit since the profit from selling each type of houses differ from one to another. Therefore, the decision variables, in this case, are the number of houses sold for each type. Since there three types of houses, there are three decision variables. Suppose $\mathrm{X}_{1}, \mathrm{X}_{2}$ and $\mathrm{X}_{3}$ are used to express the three decision variables, so:

$\mathrm{X}_{1}=$ the number units built for T40

$\mathrm{X}_{2}=$ the number units built for $\mathrm{T} 70$

$\mathrm{X}_{3}=$ the number units built for $\mathrm{T} 100$

\subsection{The Objective Function}

An objective function is a mathematical model of decision variables that are intended to be maximized or minimized, subject to given constraints.

Since the purpose of the current study is to optimize profit, so the decision variables of the current optimization are the number of units produced in each type of houses. Hence, the number of unit production of each type of houses and the amount of the profit obtained in each type will stipulate the objective function of the current optimization process.

In formulating the objective function mathematically, it is necessary to transform the context of the profit maximization into an appropriate mathematical model. Suppose C1, C2 and C3 are the profit gained from selling T40, T70 and T100 respectively and let $Z$ as the objective function. Since $X_{1}$ is the number of units built for T40, and $X_{2}$ and $X_{3}$ is the number of units built for T70 and T100 respectively, so the general form of the objective function to gain a maximal profit of the current situation can be modelled as follows:

$$
Z=C 1 X_{1}+C 2 X_{2}+C 3 X_{3}
$$

Concerning Table 1, C1 is 100 million. Meanwhile, C2 and C3 are 150 million and 180 million, respectively. So, equation 1 can be redefined as (in a unit of million of Indonesian rupiahs):

$$
Z=100 X_{1}+150 X_{2}+180 X_{3}
$$

In the current study, this last equation is considered as the objective function that will be optimized to gain a maximal profit. Note that such an objective function is applied to both locations.

\subsection{The Constraint Functions}

Linear programming is a method of transforming optimization cases into mathematical models represented in linear relationships to gain the best decision, either to maximize (e.g. profit) or to minimize (e.g. cost of production), subject to given constraints. Constraints, in this case, define the limitations of the decision. In other words, the 
constraints are the conditions that the decision must satisfy within the context of optimization.

As has been described before (see table 1), it is identified that there are a number of constraints that delimit the profit maximization of the housing development in the current case study. Those constraints are required to be transferred into mathematical models in order to be able to analyze in linear programming method. Each of the constraints is explained below.

\subsubsection{Construction area}

The first constraint relates to the limitation of the size of the land for the construction. There are $20,000 \mathrm{~m}^{2}(2$ hectares) available. There are three types of houses will be built where each takes the different size of land. The first type, T40, takes $100 \mathrm{~m}^{2}$. Meanwhile, the other two types, T70 and T100, are built on $200 \mathrm{~m}^{2}$ and $350 \mathrm{~m}^{2}$ respectively. It implies that the land size for constructing those types of houses cannot exceed the available land size. For example, we cannot build more than 57 units of T100 or 100 units for each T40 and T70 respectively since it takes more than 20,000 $\mathrm{m}^{2}$. For each $\mathrm{X}_{1}, \mathrm{X}_{2}$ and $\mathrm{X}_{3}$ are T40, T70 and T100, respectively; this constraint can be expressed as follows (in the unit of square meters):

\subsubsection{Capital production}

$$
100 X_{1}+200 X_{2}+350 X_{3} \leq 20000
$$

Another constraint confining the profit maximization comes from the developer's capital resource. The developer has a limited amount of capital to develop the resident. For the project, they currently have provided 50,000 million (Indonesian rupiah). Each type of units spends a distinct amount of capital. To build T40, it takes 300 million. Meanwhile, 450 and 540 million are taken by T70 and T100 respectively. Mathematically, this constraint can be stated as follows (in the unit of million Indonesian rupiahs):

\subsubsection{Workforce}

$$
300 X_{1}+450 X_{2}+540 X_{3} \leq 80000
$$

It is also identified that the firm has a limited number of workers. There are 450 workers available at the moment. The workers are distributed differently in each type of houses. It should be 3 workers work for each T40, 4 and 5 workers for each T70 and T100 respectively. Such a restriction can be denoted mathematically as follows (in the unit of person):

$$
3 X_{1}+4 X_{2}+5 X_{3} \leq 450
$$

The next constraint relates to the local government policy. The policy regulates the installation of electrical power control in residential development. It states that residential developers have to build their own electrical power control if they build more than 200 houses in one residential location. If they build less than or maximally 200 houses, they may use the available public electrical power control. Building own electrical power control takes relatively much money and may cause a capital increase. Therefore, the firm intends to avoid it by building no more than 200 houses in the location. This constraint can be stated mathematically as:

\subsubsection{Market demand}

$$
X_{1}+X_{2}+X_{3} \leq 200
$$

Table 1 shows the difference in the market demand in each location. The distribution of the market demand of three houses at the first location is $60 \%, 30 \%$, and 10\% for T40, T70 and T100 respectively. Meanwhile, at the second location is $50 \%, 30 \%$ and $20 \%$ for T40, T70 and T100 consecutively. This difference leads to a different market demand constraint between the first and the second location. Each of the constraints is discussed separately. At the first location, the percentage of the market demand on the three houses $(60 \%, 30 \%$ and $10 \%)$ can be expressed alternatively in the form of a proportion of 6:3:1 for $\mathrm{X}_{1}(\mathrm{~T} 40), \mathrm{X}_{2}(\mathrm{~T} 70)$ and $\mathrm{X}_{3}(\mathrm{~T} 100)$ respectively. The proportion implies that for every 6 houses of T40, it should be no more than 3 houses for T70 and 1 house for T100 in order to meet the market demand. The proportion 6:3:1 moreover can be expressed separately as 6:3 and 3:1 for proportion between $\mathrm{X}_{1}$ and $\mathrm{X}_{2}$ and between $\mathrm{X}_{2}$ and $\mathrm{X}_{3}$ consecutively. These last two proportions then will be used to formulate constraints relating to the market demand for the first location.

In mathematical terms, the proportion between $X_{1}$ and $X_{2}$ can be noted as $\frac{X_{1}}{X_{2}}=\frac{6}{3}$. Since $\frac{X_{1}}{X_{2}}=\frac{6}{3}$, then $3 X_{1}-$ $6 X_{2}=0$ and $X_{1}-2 X_{2}=0$. The similar principle can be applied for the proportion between $\mathrm{X}_{2}$ and $\mathrm{X}_{3}$ resulting in the equation $X_{2}-3 X_{3}=0$. Since the proportion of 6:3:1 implies that for every 6 houses of T40, it should be no more than 3 houses and 1 house for T70 and T100 respectively, the last two equations should be expressed in the form of inequalities as the following:

$$
\begin{aligned}
& X_{1}-2 X_{2} \geq 0 \\
& X_{2}-3 X_{3} \geq 0
\end{aligned}
$$

The similar principle can be applied for formulizing the constraint of the market demand at the second location. The distribution of the market demand on the three houses at the second location is $55 \%, 30 \%$ and $15 \%$ for $\mathrm{X}_{1}$ (T40), $\mathrm{X}_{2}$ (T70) and $\mathrm{X}_{3}$ (T100) respectively. Such a distribution can be expressed mathematically as 11:6:3 for $\mathrm{X}_{1}$, $\mathrm{X}_{2}$ and $\mathrm{X}_{3}$ respectively. Such a proportion can be restated as 11:6 for the proportion of $\mathrm{X}_{1}$ and $\mathrm{X}_{2}$ and as $6: 3$ for the proportion of $X_{2}$ and $X_{3}$. These last two proportions lead to the formation of the market demand constraints at the second site. 


$$
\begin{gathered}
6 X_{1}-11 X_{2} \geq 0 \\
3 X_{2}-6 X_{3} \geq 0
\end{gathered}
$$

\subsection{Profit Maximization Model}

Regarding the aforementioned objective and the constraints functions, the model of profit maximization of the current case can be stated into a complete linear programming model. The linear programming model for the first location is stated as follows:

$$
\begin{aligned}
& \text { Maximize } Z=100 X_{1}+150 X_{2}+180 X_{3} \\
& \text { Subject to } \\
& \text { (i) } 100 X_{1}+200 X_{2}+350 X_{3} \leq 20000 \\
& \text { (ii) } 300 X_{1}+450 X_{2}+540 X_{3} \leq 80000 \\
& \text { (iii) } 3 X_{1}+4 X_{2}+5 X_{3} \leq 450 \\
& \text { (iv) } X_{1}+X_{2}+X_{3} \leq 200 \\
& \text { (v) } X_{1}-2 X_{2} \geq 0 \\
& \text { (vi) } \quad X_{2}-3 X_{3} \geq 0 \\
& \text { Where } X_{1}, X_{2}, X_{3} \geq 0
\end{aligned}
$$

Meanwhile, the linear programing model for the second location is expressed as follows:

$$
\begin{aligned}
& \text { Maximize } Z=100 X_{1}+150 X_{2}+180 X_{3} \\
& \text { Subject to } \\
& \text { (i) } \quad 100 X_{1}+200 X_{2}+350 X_{3} \leq 20000 \\
& \text { (ii) } 300 X_{1}+450 X_{2}+540 X_{3} \leq 80000 \\
& \text { (iii) } 3 X_{1}+4 X_{2}+5 X_{3} \leq 450 \\
& \text { (iv) } \quad X_{1}+X_{2}+X_{3} \leq 200 \\
& \text { (v) } 6 X_{1}-11 X_{2} \geq 0 \\
& \text { (vi) } \quad 3 X_{2}-6 X_{3} \geq 0 \\
& \text { Where } X_{1}, X_{2}, X_{3} \geq 0
\end{aligned}
$$

\subsection{Optimization Solution and Its Interpretation}

The aforementioned linear programming model of each location is then analyzed using QM software to obtain the solution for the profit maximization. In this model, the solution refers to the number of units in each type should be produced in order to obtain the maximal profit satisfying or subject to the given constraints.

Taking the linear programming model (statement 10 and 11) into QM analysis, Table 2 shows the comparison of the profit optimization solution for the two locations. The value of variable $\mathrm{X}_{1}, \mathrm{X}_{2}$ and $\mathrm{X}_{3}$ is the solution list indicating the number of houses built for T40, T70 and T100 respectively. The value of slack variables informs about the optimization or the surplus of the given resources or constraints as the result of the optimization process. Meanwhile, the optimal Value $(Z)$ indicates the maximal profit obtained from the optimization model subject to the given constraints.

Table 2. The solution list for the profit maximization of the housing development at the first and the second location

\begin{tabular}{lrrr}
\hline \multicolumn{1}{c}{ Variable } & The First Site & The Second Site & Unit \\
\hline X1 & 77 & 75 & House \\
X2 & 39 & 41 & House \\
X3 & 13 & 12 & House \\
slack 1 (land) & 71 & 0 & Square meter \\
slack 2 (capital) & 2,557 & 2,462 & Million \\
slack 3 (workforce) & 0 & 0 & Person \\
slack 4 (total unit) & 71 & 72 & House \\
slack 5 (market demand 1) & 0 & 0 & - \\
slack 6 (market demand 2) & 0 & 48 & - \\
Optimal Value (Z) & 15,814 & 15,846 & Million \\
\hline \hline
\end{tabular}

For the first location, the maximal profit gained by the firms under the given constraints is 15,814 million. To obtain such a profit, the firm should build 129 houses consisting of 77 houses of T40, 39 houses of T70 and 13 houses of T100 (see the value of X1, X2 and X3). Slack 1 indicates that there are 71 square meters of the available 20,000 square meters are unbuilt. This implies that not all the available area of the construction has been used for the house building. The surplus is also found in capital production (slack 2) where there are 2,557 million from 50,000 million are unspent. Meanwhile, there is no surplus in the workforce (slack 3), implying that all workers are employed. Slack 4 expresses that the solution of the total of the houses built needs 71 houses more to reach 200 houses (the maximal house to be built based on the fourth constraint). This implies that the number of built 
houses satisfies the firm's restriction to build maximally 200 houses.

Meanwhile, for the second location, the result of the profit optimization shows that the maximal profit obtained under the given constraints is 15,846 million by building 75 T40s, 41 T70s and 12 T100s. So, there are 128 houses built. The value of slack 1 indicates that all the available land is used for housing. Meanwhile, slack 2 means that there are 2,462 million remaining from 50,000 million invested capital for the production. All available workers are employed. It is indicated by the value of slack 3 . Similar to the first location, slack 4 expresses that the solution of the total of the houses built needs 72 houses more to reach the restricted 200 houses. This implies that the number of built houses is in line with the firm's expectation to build maximally 200 houses.

\subsection{Sensitivity Analysis}

Nowadays, the environment of a business is difficult to be predicted and is very unstable. As a result, a business decision is easily be influenced by other external factors that predispose business cost or profit. Hence, a crucial business decision needs to be analyzed its sensitivity regarding the potential related changes.

In the context of profit maximization, sensitivity analysis is an analysis to identify the amount by which we can change the input data (for example the RHS values of the constraint functions) for the output of the optimization of a linear programming model to remain comparatively unchanged. Suppose there are two linear programming models of optimization. If a small change of RHS of the first model produces a significant change in its optimization solution while a correspondingly small change of RHS of the second model doesn't affect its optimization solution as much, it can be concluded that the first model is more sensitive while the second model is less sensitive to the change in the input data.

The purpose of sensitivity analysis of the current study is to identify the key variables or constraints that are major influence the obtained solution of the profit maximization. Such identification will help the developer to assess whether the change on the input of key variables or constraints will affect the project decision. Such a sensitivity analysis are categorized into two forms, namely sensitivity analysis on the decision variables (the objective function) and sensitivity analysis on the constraints (the constraint functions).

3.7.1. Sensitivity analysis on the objective function

The sensitivity analysis on the objective function refers to identify the possible change on the optimization solution and on the obtained profit as the result of the change on the parameters or the coefficient of the objective function. Table 3 shows the result of the sensitivity analysis on the objective function or the decision variables. The first column represents the decision variables that is the number of unit production for each house type, namely $\mathrm{X}_{1}$ for T40, $\mathrm{X}_{2}$ and $\mathrm{X}_{3}$ for T70 and T100 respectively. The second column tells about the location of the development. The third column shows the value of $X_{1}, X_{2}$ and $X_{3}$ in each location to obtain the maximal profit. The fourth column represents the parameter values of $X_{1}, X_{2}$ and $X_{3}$. The fifth and the sixth column inform the lower and the upper bound of the parameter values of $X_{1}, X_{2}$ and $X_{3}$. Meanwhile, the seventh column shows the range between the lower and the upper bound of the parameters.

In the current sensitivity analysis, the parameters of each decision variables are studied for their impact on the optimization solution and on the profit change.

Table 3. Sensitivity analysis on the objective function

\begin{tabular}{llrrrrrr}
\hline Variable & Location & Value & $\begin{array}{l}\text { Original Val } \\
\text { (parameter) }\end{array}$ & Lower Bound & Upper Bound & Discrepancy \\
\hline \multirow{2}{*}{$\mathbf{1}$} & \multicolumn{1}{c}{$\mathbf{2}$} & $\mathbf{3}$ & $\mathbf{4}$ & $\mathbf{5}$ & $\mathbf{6}$ & \\
& The first & 77 & 100 & -105 & 105 & 210 \\
$\mathrm{X} 2$ & The second & 75 & 100 & 26 & 105 & 79 \\
& The first & 39 & 150 & 129 & 160 & 31 \\
$\mathrm{X} 3$ & The second & 41 & 150 & 138 & 159 & 21 \\
& The first & 13 & 180 & 175 & Infinity & Infinity \\
& The second & 12 & 180 & 175 & 213 & 38 \\
\hline \hline
\end{tabular}

According to Table 3 , the value of lower and upper bound suggest that the change on the parameter $\mathrm{X}_{1}$ (the original value) will not alter the obtained optimization solution if the parameter is substituted by any value between the lower and the upper bound. For example, at the first location, the value for the lower and upper bound of $X_{1}$ is -105 and 105 , respectively, with the original value is 100 (the parameter of $X_{1}$ ). If the parameter of $X_{1}$ is replaced by 105 , the optimization solution will remain the same that is 77,39 and 13 for X1, X2 and X3 respectively. However, if the parameter is substituted by 106 (out of the upper bound), the optimization solution will differ from the previous one. The similar principle is also applied for the parameter of $X_{2}$ and $X_{3}$. The infinity value means that there is no bound for the related bounding. For example, in the first location, the optimization solution will remain the same even though the parameter of $X_{3}$ (the original value of $X_{3}$ ) is replaced by any value that is more than 175. It can be concluded that the optimization solution will remain the same even though there are changes in the parameters of the decision variables as long as the changes are within the value of lower and upper bound.

It also implies that the discrepancy between the lower and upper bound indicates the sensitivity of the 
optimization solution. If the values of the discrepancies between the first and the second location are compared, it may be concluded that the second location is more sensitive to changes than the first location. It can be traced from the fact that the discrepancy values at the second location tend to be smaller than that in the first location. Once an optimization solution is rather sensitive, the solution will be easily affected by the changes in their parameters and constraints or other external economic factors. Hence, the optimization solution for the first location is more stable than that of the second location.

Furthermore, the value of the lower and the upper bound also give impacts on the value of the obtained profit. In the case of the current study, the change in the parameters (the original value, see Table 3 ) will cause the change (increase or decrease) on the obtained profit. The amount of change on the obtained profit is determined by the value of the corresponding decision variables (the second column of Table 3 ). For instance, if the parameter of $\mathrm{X}_{1}$ is changed to be 101, the optimization solution remains the same, but the obtained profit (the value of $Z$ ) increases by 77 . However, if the parameter is switched to be 99 , the profit will decrease by 77 . It is also applied for the other two parameters, $X_{2}$ and $X_{3}$. The sensitivity analysis informs the developer about the possible changes that they can make without change the optimization solution. The lower and the upper bound assist the developer in making such a possible change to improve the profit without changing the initial optimization solution. It means that the developer can still optimize their obtained profit by manipulating the unit profit (the decision-variable parameters) within the range of the lower and upper bound subject to the given constraints.

Concerning the effect of changes on the parameters toward the profit, it is more profitable to invest in the first location rather than in the second location. At the first location, the developer has a more flexible decision to adjust the parameters in order gain a more maximal profit with the condition that there is no change in the given constraints since the discrepancy at the first location is relatively broader and higher than that in the second location. 3.7.2. Sensitivity analysis on the constraint functions

The sensitivity analysis on the constraints refers to the analysis on the possibility of changes of the optimization solution as the result of the change on the value of the RHS (Right Hand Side) of the constraint functions. Table 4 shows the result of the sensitivity analysis on the constraint functions in both locations. The first column represents the constraints of the optimization. The second column tells about the locations of the development. The third column shows the RHS value of each given constraint function. The fourth and the fifth column inform about the lower and the upper bound of the value of RHS. Meanwhile, the sixth column shows the range between the lower and the upper bound of the RHS value.

Table 4. Sensitivity analysis on the constraint functions.

\begin{tabular}{|c|c|c|c|c|c|}
\hline Constraints & Location & $\begin{array}{l}\text { Original Val } \\
\text { (RHS) }\end{array}$ & $\begin{array}{l}\text { Lower } \\
\text { Bound }\end{array}$ & Upper Bound & Discrepancy \\
\hline 1 & 2 & 3 & 4 & 5 & 6 \\
\hline Construction & The first & 20,000 & 19,929 & Infinity & Infinity \\
\hline (square meter) & The second & 20,000 & 18,158 & 20938 & 2,780 \\
\hline \multirow{2}{*}{$\begin{array}{l}\text { Capital } \\
\text { (million) }\end{array}$} & The first & 50,000 & 47,443 & Infinity & Infinity \\
\hline & The second & 50,000 & 47,538 & Infinity & Infinity \\
\hline \multirow[t]{2}{*}{ Workforce (person) } & The first & 450 & 0 & 452 & 452 \\
\hline & The second & 450 & 430 & 474 & 44 \\
\hline \multirow{4}{*}{$\begin{array}{l}\text { Unit of Construction } \\
\text { (houses) } \\
\text { Market Demand } 1\end{array}$} & The first & 200 & 129 & Infinity & Infinity \\
\hline & The second & 200 & 128 & Infinity & Infinity \\
\hline & The first & 0 & -2 & 150 & 152 \\
\hline & The second & 0 & -525 & 142 & 667 \\
\hline \multirow[t]{2}{*}{ Market Demand 2} & The first & 0 & -2 & 45 & 47 \\
\hline & The second & 0 & -infinity & 48 & Infinity \\
\hline
\end{tabular}

The value of lower and upper bound indicates the range of the changes on the RHS values of the constraint functions (e.g. the original value) that do not impact on the optimization solution. For example, at the first location, the range of changes of RHS value of the constraint relating to the construction area that does not change the optimization solution is between 19,929 and Infinity. It means that if the firm enlarges the area of the construction, suppose 30,000 square meters; the optimization solution remains the same as if it is 20,000 square meters. But, if the change is out of the range, the optimization solution will differ. The infinite value of the upper bound of capital production means that the optimization solution will remain the same even though the developer spent more capitals on the project as much as possible. However, if the developer reduces the capital, such that it is less than 47,443 (under the lower bound), the optimization solution will be impacted.

Hence, the result of the sensitivity analysis on each constraint function shown on Table 4 inform the developer about the range of changes (i.e. the values of the lower and the upper bound) that they can make on RHS value without impacting the optimization solution. In the world of business or industries where situations are not stable, changes on constraint functions may happen unexpectedly. As long as the changes are in the range of lower and upper bounds, businessmen do not need to change their economic strategies or plans. 
If the discrepancies between lower and upper bound are being considered in both locations, it is identified that the optimization solution of the first location is more stable to change than that of the second location. It can be traced from the discrepancies of constraints relating to the available resources, such as the land area, the capital, and the workforce. Where those three constraints significantly affect the maximal profit of the project. It implies the change in the given constraints will not really affect the initial optimization solution. Having such a stable optimization solution to some extent gave benefit for the developer where they do not need to change their economic strategies or plans as long as the changes are in the range of the given lower and upper bounds.

\subsection{Remarks on the Optimization Solution}

Considering the optimization results of the two locations, it is identified that developing housing in the second location produces more profit than that on the first location by 32 million. Moreover, the available land is used more efficiently in the second location since the whole land is used for the housing altogether, no land left. Meanwhile, there are 71 square meters remained unbuilt in the first location.

However, if slack 5 and 6 (the slacks relating to the market demand) are taken into account (see table 2), the distribution of the number of the houses in the first location (the optimization solution) is more compatible with the given market demand comparing to that in the second location. It is indicated by the absence of surplus in the slack 5 and 6 of the first location. This state, to some extent, gives a benefit for the developer since the distribution of the houses is close to the market demand causing the houses to be sold quickly and maximally.

Although the second location produces a higher profit, there is much more capital invested in the second location comparing to that in the first location. It is indicated by the different amount of capital surplus between the two locations (see slack 2 of table 2). From 50,000 available capital, 2,557 million are unspent in the first location while 2,462 million are in the second location. It means that there is only 47,443 million capital spent in the first location, which is significantly less than that in the second location (47.538 million). The discrepancy reaches 95 million.

Once return on investment (ROI) being considered, both locations have the same amount of ROI, that is $33 \%$. It means that the higher profit obtained from the second location does not imply that the location is more profitable than the first location. Its higher profit is due to a higher investment given to the location.

In addition, the use of land in the optimization solution of the first location seems to be not optimal since there are remaining unbuilt area (see slack 1 table 2). However, it can be turned into another income for the firm once it is treated as another object to be sold.

Moreover, the sensitivity analysis on the objective and the constraint functions shows that the optimization solution of the first location is more stable to potential changes than that on the second location. It implies the change in the given constraints will not really affect the optimization solution. Hence, the developer does not need to make major adjustment once an acceptable change occurred on the given constraints.

Regarding the aforementioned arguments, it can be concluded that although investing in the second location leads to gain a more profit; it is more recommended to invest in the first location due to several reasons. First, its optimization solution is more relevance to its market demand. Second, investing in the first location need less capital than that in the second location. Third, since both locations have similar ROI, the higher the profit obtained in the second location tends to be a relative or notional profit. Fourth, the drawback founded in the first location can be turned to another benefit for the developer to gain more profit. The last, the optimization solution of the first location is more stable to change than that of the second location due to changes in the parameters of the objective function and the constraints.

\section{Conclusion}

The current research shows how to perform a profit maximization procedure with respect to market demand by means of linear programming to determine the most profitable economic activities. It shows how to analyze the optimization solutions of linear programming and their sensitivities to identify the key factors influencing the profit maximization, which then can be used as the basis to decide the most profitable business.

The comparative analysis of the optimization solutions of the two cases implies that selecting a business activity based simply on its profit may lead to an improper business decision. An example from the current study shows that although the second location more profitable (since it generates a higher profit) than the first location, the analysis on the optimization solutions and their sensitivities shows that the first location is more relevance to its market demand comparing to that of the first location. Moreover, it is noted that the higher profit obtained in the second location tend to be relative or notional since both locations result in the same return on investment (ROI). It also found that investing in the first location need less capital than that in the second location to generate a similar return on investment (ROI). In addition, the sensitivity analysis on the objective and the constraint functions shows that the optimization solution of the first location is more stable to change than that of the second location due to changes in the parameters of the objective function and the given constraints. 


\section{References}

Aboelmagd, Y. M.R. (2018) Linear programming applications in construction locations. Alexandria Engineering Journal (2018) 57, 4177-4187

Ahmadi-Javid, A., Amiri, E., \& Meskar, M. (2018) A Profit-Maximization Location-Routing-Pricing Problem: A Branch-and-Price Algorithm. European Journal of Operational Research, Volume 271, Issue 3, 16 December 2018, Pages 866-881.

Anderson, David R., Sweeney, Dennis J., Williams, Thomas A., Camm, Jeffrey D., \& Martin, K. (2012) An Introduction to Management Science: Quantitative Approaches to Decision Making, Revised Thirteenth Edition. OH: South-Western Cengage Learning.

Cezik, T., \& P. L'Ecuyer (2006) Staffing multiskill call centers via linear programming and simulation. Management Science, forthcoming.

Florez, L., Castro-Lacouture, D., Medaglia, A.L. (2012) Sustainable workforce scheduling in construction program management, J. Oper. Res. Soc. 64 (8) (2012) 1169-1181, https://doi.org/10.1057/jors.2012.164.

García-Nieves, J.D., Ponz-Tienda, J.L., Ospina-Alvarado, A. \& Bonilla-Palacios, M. (2019) Multipurpose linear programming optimization model for repetitive activities scheduling in construction projects. Automation in Construction 105 (2019) 102799

Goetschalckx, M., Vidal, C.J. Dogan, K. (2002) Modeling and design of global logistics systems: A review of integrated strategic and tactical models and design algorithms. European Journal of Operational Research. Volume 143, Issue 1, 16 November 2002, Pages 1-18

Guide, V.D.R., Teunter, R.H., \& Wassenhove, L.N.V. (2003) Matching Demand and Supply to Maximize Profits from Remanufacturing. Manufacturing \& Service Operations Management 5(4):303-316. http://dx.doi.org/10.1287/msom.5.4.303.24883

Guo, X. \& Xu, D. (2016) Profit maximization by a private toll road with cars and trucks. Transportation Research Part B 91 (2016) 113-129.

Hasanah, U. \& Ahmad, A. (2018) Linier Programing dalam Manajemen Keuntungan Proyek Perumahan Subsidi. SENTIA, Vol. 10 No. 1. http://sentia.polinema.ac.id/index.php/sentia2018/article/view/292

Hassani, A. P., \& Akhtar, M. (2015) Use of linear programming model to determine the optimum cropping pattern: a case study of Punjab. Electronic Journal of Environmental, Agricultural and Food Chemistry (EJEAFChe) 4(1): 841-850.

Hildenbrand, W. (1994) Market Demand: Theory and Empirical Evidence. Princeton, New Jersey: Princeton University Press.

Igwe, K.C., Onyenweaku C.E., \& Tanko, L., (2013) A linear programming approach to combination of crop, monogastric farm animal and fish enterprises in Ohafia agricultural zone, Abia State, Nigeria. Global Journal of Science Frontier Research (GJSFR): (D) Agriculture \& Veterinary 13(3): 23-32.

Jaslam, P.K. M., Joseph, B., Kumar, V., \& Kumar, N.S. (2017) Statistical Model for Profit Maximization of Homesteads in Southern Laterite Agro-Ecological Unit. Indian Journal of Ecology (2017) 44(4): 778-783

Khanra, A. Maiti, M.K., Maiti, M. (2015) Profit maximization of TSP through a hybrid algorithm. Computers \& Industrial Engineering, Volume 88, October 2015, Pages 229-236.

Levitt, Steven D. (2015) Bagels and Donuts for Sale: A Case Study in Profit Maximization, Research in Economics, http://dx.doi.org/10.1016/j.rie.2015.11.001

Liu, Shiang-Tai (2006) A geometric programming approach to profit maximization. Applied Mathematics and Computation 182 (2006) 1093-1097

Maurya, V.N., Misra, R.B., Anderson, P.K., Shukla, K.K. (2015) Profit Optimization Using Linear Programming Model: A Case Study of Ethiopian Chemical Company. American Journal of Biological and Environmental Statistics. Vol. 1, No. 2, 2015, pp. 51-57. doi: 10.11648/j.ajbes.20150102.12

Mazidi, P., Tohidi, Y., Ramos, A., \& Sanz-Bobi, M.A., (2018) Profit-maximization generation maintenance scheduling through bi-level programming. European Journal of Operational Research, Volume 264, Issue 3, 1 February 2018, Pages 1045-1057

Narver, John C. \& Slater, Stanley F. (1990). The Effect of a Market Orientation on Business Profitability. Journal of Marketing Volume: 54 issue: 4, page(s): 20-35. https://doi.org/10.1177/002224299005400403

Onoriode, O.H., \& Ighoroje, E.J. (2018) Impact of Linear Programming on Profit Maximization in Production Firms: A Survey of Selected Firms in Delta State of Nigeria. Pyrex Journal of Business and Finance Management Research. Vol. 4 (4) pp. 30-37.

Rohmah, W.G., Purwaningsih, I., Santoso, S. .M., (2018) Applying linear programming model to aggregate production planning of coated peanut products. International Conference on Green Agro-industry and Bioeconomy. IOP Conf. Series: Earth and Environmental Science 131 (2018) 012035 doi :10.1088/17551315/131/1/012035.

Stripling, E. Broucke, S.V., Antonio, K., Baesens, B., Snoeck, M. (2018) Profit maximizing logistic model for customer churn prediction using genetic algorithms. Swarm and Evolutionary Computation, Volume 40, June 
2018, Pages 116-130

Torres, D., Crichigno, J., Padilla, G., Rivera, R. (2014) Scheduling coupled photovoltaic, battery and conventional energy sources to maximize profit using linear programming. Renewable Energy 72 (2014) 284-290

Wijeratne, N. and Harris, F.C. (1984) Capital budgeting using a linear programming model, International Journal of Operations \& Production Management, 4(2), pp.49-64, 1984.

Wu, J. \& GE, X. (2012) Optimization Research of Generation Investment Based on Linear Programming Model. Physics Procedia 24 (2012) $1400-1405$.

Yahya, W.B., Garba, M. K., Ige, S. O. (2018) Profit Maximization In A Product Mix Company Using Linear Programming. European Journal of Business and Management. Vol. 4, No.17. pp. 126 - 131 